Research Paper

\title{
A Quick Responsive Fluorogenic pH Probe for Ovarian Tumor Imaging
}

\author{
Ching-Hsuan Tung ${ }^{1,2,3}$, Jianjun Qi ${ }^{1}$, Lingchuan $\mathrm{Hu}^{1}$, Myung Shin Han ${ }^{3}$, and Young Kim ${ }^{3,4}$ \\ 1. Department of Translational Imaging, Houston Methodist Research Institute; \\ 2. Department of Obstetrics and Gynecology, Houston Methodist Hospital, Houston, TX, USA \\ 3. Molecular Imaging Innovations Institute, Department of Radiology, Weill Cornell Medical College, New York, NY, USA \\ 4. Department of Pathology, Chonnam National University Hospital, Gwangju, Korea
}

$\bowtie$ Corresponding author: Ching H. Tung, Weill Cornell Medical College, 413 East 69th Street, Box 290, New York, NY 10021. E-mail: cht2018@med.cornell.edu

(c) 2015 Ivyspring International Publisher. Reproduction is permitted for personal, noncommercial use, provided that the article is in whole, unmodified, and properly cited. See http://ivyspring.com/terms for terms and conditions.

Received: 2015.05.28; Accepted: 2015.07.09; Published: 2015.08.01

\begin{abstract}
A novel cell-permeable compound, $\mathrm{CypH}-1$, that is non-fluorescent at neutral $\mathrm{pH}$, but fluoresces under mildly acidic conditions with a near infrared maximum emission wavelength was designed for the detection of tumors in the clinical setting. The potential of $\mathrm{CypH}-1$ in ovarian cancer imaging was demonstrated using a murine model. The intraperitoneally administered CypH-1 results in a robust fluorescence signal of discrete neoplastic lesions with millimeter range resolution within few hours. Moreover, fluorescence signal is strikingly enhanced at peripheral regions of tumors at the microscopic level suggesting a sharp physiological difference at the tumor/normal tissue interface. This robust acid-activated imaging agent is expected to have significant impact in broad surgical and diagnostic applications.
\end{abstract}

Key words: fluorogenic dye, $\mathrm{pH}$ indicator, tumor microenvironment, acidic, ovarian cancer.

\section{Introduction}

The tumor microenvironment constitutes a complex system that includes tumor cells, immune cells, fibroblasts, vascular structures, and an extracellular matrix rich in signaling molecules $[1,2]$. Neoplastic lesions are not self-sufficient in their propagation and require otherwise normal supporting cells and proliferative or protective factors within this dynamic milieu. A key feature of this microenvironment is the mildly acidic condition generated by the altered metabolism also known as the "Warburg effect" of tumors and relative hypoxia [3-5]. The intracellular $\mathrm{pH}\left(\mathrm{pH}_{\mathrm{i}}\right)$ and extracellular $\mathrm{pH}\left(\mathrm{pH}_{\mathrm{e}}\right)$ in cancerous cells are distinct from normal cells. In non-neoplastic cells the $\mathrm{pH}_{\mathrm{i}}$ and $\mathrm{pH}_{\mathrm{e}}$ are 7.2 and 7.5, respectively; but in cancer cells, the $\mathrm{pH}_{\mathrm{i}}$ is 7.5 and the $\mathrm{pH}_{\mathrm{e}}$ is $~ 6.4-7.1$ [4, 6-8]. To maintain their rapid growth and proliferation, cancer cells have a higher need for energy which is partially satisfied by greater reliance on alternate, albeit less efficient, metabolic pathways. Under aero- bic conditions, cancer cells metabolize glucose to lactic acid, instead of pyruvate, which usually enters the Krebs cycle in normal cells under non-stress conditions. In combination with relatively poor perfusion, the lactic acid generated by this process lowers the $\mathrm{pH}_{\mathrm{e}}$. Recent studies indicate that by maintaining a relatively low $\mathrm{pH}$ in their microenvironment cancer cells can escape immune detection [4, 7]. In addition, the acidic environment promotes or facilitates the action of many proteases that are involved in tissue remodeling and tumor invasion $[9,10]$. Indeed, areas of low $\mathrm{pH}$ often observed at tumor boundaries correspond to high proteolytic activity [10], supporting an intimate role of extracellular acidification in several hallmarks of cancer [1].

Acidic tissue microenvironments and intracellular compartments have been identified as targets for imaging [11-15] and treatment [16-18]. Numerous $\mathrm{pH}$ responsive dyes have been developed to study vari- 
ous processes in cells and in animals.[19] Near infrared (NIR) $\mathrm{pH}$ sensitive dyes, which have better tissue propagation properties, have been specially developed for potential in vivo imaging [20-25]. Assisted by targeting ligands such as RGD [26], glucosamine [27], cathepsin binding substrates [28], or antibodies, these NIR dye conjugates, which are predominantly investigated by intravenous (IV) delivery, are able to bind to their targets preferentially and are efficiently internalized through the endocytosis process. The fluorescence intensity observed is reflective of the $\mathrm{pH}$ condition found in endosomes or/and lysosomes, but not of the extracellular acidic environment in tumor cells. Some tumors such as ovarian, cervical, and colon cancers are superficial; therefore, it is possible that a simple $\mathrm{pH}$ dye, without a complex targeting moiety, could be locally applied to highlight the tumor margin through a direct contact with the acidic environment. To the best of our knowledge, none of the reported $\mathrm{pH}$ dyes have been applied directly to the surgical area.

Due to the absence of identifying symptoms in early disease and the lack of effective screening methods, most ovarian cancers are diagnosed at an advanced stage. Once diagnosed, cytoreductive surgery is usually performed to debulk tumor. It has been confirmed that a maximal removal of the diseased tissues leads to the best overall outcome [29]. The incomplete removal of the primary tumor by surgery ultimately results in disease recurrence [30]. Large tumors, which are readily seen by surgeons, require no assistance for detection during the procedure, but smaller lesions that may be imperceptible by surgeons could be the source of poor treatment outcome. Several intravenously administered fluorescence-imaging probes have been proposed to guide the surgical procedure [31-33]. However, we recently found that the intraperitoneally (IP) injected probe has a better labeling efficiency than the IV delivered probes for small ovarian cancer lesions, probably due to the poorly developed vasculature [34]. As these small lesions are superficial, their acidic microenvironment represents an attractive target for a $\mathrm{pH}$-sensitive molecular imaging agent. Delivered IP, a $\mathrm{pH}$-probe could be capable of generating a fluorescence signal suitable to detect small lesions. Here we report on the development of a rationally designed fluorogenic $\mathrm{pH}$-sensitive molecular probe for small lesion detection.

\section{Materials and Methods}

\section{Synthesis and Characterization of Dye CypH-1}

All chemicals and solvents were purchased from Sigma-Aldrich (St. Louis, MO). 4-(Dimethylamino) phenol [35] (57 mg, $0.42 \mathrm{mmol})$ in DMF (5 ml) was reacted with sodium hydride $(17 \mathrm{mg})$ at $\mathrm{RT}$ for $15 \mathrm{~min}$ [36]. IR-775 (100 mg, $0.19 \mathrm{mmol}$, Dye content 90\%) was added slowly and stirred at RT overnight. The reaction was extracted with dichloromethane (DCM), and washed with brine. The product in DCM layer was purified by silica gel column using DCM/MeOH (MeOH $0-10 \%)$ as an elution solvent. The yield is 57 $\mathrm{mg}$, 48\%. TLC: $\mathrm{DCM} / \mathrm{MeOH}=10 / 1, \mathrm{R}_{\mathrm{f}}=0.25 .{ }^{1} \mathrm{H}-\mathrm{NMR}$ $\left(300 \mathrm{MHz}, \mathrm{CDCl}_{3}\right): 7.87(2 \mathrm{H}, \mathrm{d}, \mathrm{J}=14.1 \mathrm{~Hz}), 7.71(2 \mathrm{H}, \mathrm{d}$, $\mathrm{J}=7.8 \mathrm{~Hz}), 7.41-7.35(2 \mathrm{H}, \mathrm{m}), 7.31(2 \mathrm{H}, \mathrm{d}, \mathrm{J}=6.3 \mathrm{~Hz})$, $7.25(2 \mathrm{H}, \mathrm{d}, \mathrm{J}=7.5 \mathrm{~Hz}), 7.21-7.16(2 \mathrm{H}, \mathrm{m}), 7.09(2 \mathrm{H}, \mathrm{d}$, $\mathrm{J}=7.8 \mathrm{~Hz}), 6.00(2 \mathrm{H}, \mathrm{d}, \mathrm{J}=14.1 \mathrm{~Hz}), 3.58(6 \mathrm{H}, \mathrm{s}), 3.13$ $(6 \mathrm{H}, \mathrm{s}), 2.75-2.65(4 \mathrm{H}, \mathrm{m}), 2.05-2.00(2 \mathrm{H}, \mathrm{m}), 1.36(12 \mathrm{H}$, s). ${ }^{13} \mathrm{C}-\mathrm{NMR}$ (125MHz, MeOD): 172.77, 163.72, 158.83, $142.55,141.99,140.78,139.21,128.72,125.44,122.28$, 122.08, 116.23, 110.26, 100.12, 49.02, 45.67, 31.22, 27.63, 24.18, 20.92. MS: $584\left(\mathrm{M}^{+}\right)$. Full spectroscopic analysis, quantum yield and $\log P$ measurements were included in the Supporting Information.

\section{General Information of Biological Experiments}

The human SKOV3 cervical cancer cell line was obtained from the American Type Culture Collection (ATCC, Manassas,VA). The luciferase transfected GFP+ SKOV3 (SKOV3/GFP-Luc) cells were purchased from Cell Biolabs (San Diego, CA). The cell lines were maintained in McCoy's 5A Medium, supplemented with $10 \%$ fetal bovine serum, $1 \%$ antibiotics (penicillin-streptomycin) at $37^{\circ} \mathrm{C}$ under $5 \% \mathrm{CO}_{2}$. Lyso Tracker Red, Mito Tracker Green, ER Tracker Blue and Hank's balanced salt solution (HBSS) were purchased from Life Technologies (Grand Island, NY).

\section{Cellular Distribution of CypH-1}

SKOV3 $\left(5 \times 10^{3} /\right.$ well $)$ were seeded in a 96 -well plate for $20 \mathrm{hrs}$. Cells were incubated in phenol red free DMEM (Hyclone, Logan, UT) with 10\% FBS and $1 \%$ antibiotics with the presence of CypH-1 $(0.5 \mu \mathrm{M})$ for 30 mins at $37^{\circ} \mathrm{C}$. Cells were then washed using HBSS (4 X), followed by incubation with Lyso Tracker Red $(0.5 \mu \mathrm{M})$, Mito Tracker $(0.5 \mu \mathrm{M})$ or ER Tracker $(0.5$ $\mu \mathrm{M})$ for 20-30 min. The concentration and labeling conditions of each tracker used was that suggested by the manufacturer. Cells were then washed with HBSS $(4 \mathrm{X})$ and incubated with fresh complete medium (phenol-red free) for $20 \mathrm{~min}$ before fluorescence imaging.

Fluorescent microscopic images of live cells were acquired using an inverted fluorescence microscope (Olympus 81X; Tokyo, Japan). The fluorescence image of CypH-1 was collected through a cy7 filter set (excitation 675-745 nm, emission 765-855 nm), Lyso Tracker Red was obtained through the TRITC band pass filter set (excitation: 510-550 nm, emission: 
573-648 nm), Mito Tracker Green was obtained through the FITC filter set (excitation: 450-490 nm, emission: 500-550 nm), and ER Tracker Blue was taken via the DAPI filter set (excitation: $325-375 \mathrm{~nm}$, emission: $435-485 \mathrm{~nm}$ ).

\section{In Vivo Imaging of Abdominal Tumor with CypH-1}

All animal studies were performed in compliance with the approved animal protocols and guidelines of Institutional Animal Care and Use Committee of Houston Methodist Research Institute. BALB/c $\mathrm{Nu} / \mathrm{Nu}$ female nude mice $(\mathrm{n}=16)$ were bought from Charles River (Wilmington, MA). SKOV3/GFP-Luc (5 $x 10^{6}$ ) cells were injecting intraperitoneally (IP) into the abdomen of 5 weeks old nude mice. Tumor growth was followed by luciferase imaging. After two weeks of initial tumor inoculation, CypH-1 (20 nmol) dissolved in 2.5\% DMSO (100ul) was administrated IP. Animals were sacrificed in $3 \mathrm{hrs}$ and imaged under GFP and NIR channel using the IVIS 200 system (PerkinElmer, Waltham, MA). The GFP signal is used to locate tumors. The GFP signal was collected using a 445-490 $\mathrm{nm}$ excitation and 515-575 $\mathrm{nm}$ emission filter set, while CypH-1 signal was collected using 710-760 $\mathrm{nm}$ excitation and $810-875 \mathrm{~nm}$ emission filter set. Signal to background ratio was performed selecting specific ROI (Region of Interested) using IVIS software.

Major organs were collected immediately following the whole body imaging. Signal of micro tumors and normal tissues on each organ, including kidneys, livers, spleens, stomachs, intestines and tumors, were imaged ex vivo using a Maestro imaging system (CRI, Waltham, MA). The GFP signal was collected using 445-490 $\mathrm{nm}$ excitation and $515 \mathrm{~nm}$ long pass emission filter set. The CypH-1 signal was collected using 710-760 nm excitation and $800 \mathrm{~nm}$ long pass emission filter set. Tumor to Organ Ratio (TOR) was determined by measuring mean fluorescence intensities for each tissue and tumor.

Imaging tissue sample data were gained from total of 16 mice from 4 independent experiments and fluorescence signal (NIR or Green) were quantified using ROI measurement. Statistical analysis was performed using Student-t test method. Differences with $p$ values of less than or equal to 0.05 were considered statistically significant.

\section{Histology}

The tissue samples (either tumor or normal tissues with tumor attached on it) were frozen in OCT
(Tissue-Tek ${ }^{\circledR}$, Sakura Finetek, Torrance, CA) in $-20^{\circ} \mathrm{C}$ for $20 \mathrm{~min}$. Then the frozen tissues were cut into $10 \mu \mathrm{m}$ thickness using Thermo Scientific Microm HM550 cryostat and mounted with the medium with DAPI (Vector Laboratories Inc., CA, USA). The images were captured with a fluorescence microscope (EVOS® FL Life technologies) and analyzed by a pathologist. The fluorescence images of tissues obtained through a Cy7 filter (excitation: 710/40, emission: 775/46) for CypH-1 and a DAPI filter (excitation: 357/44, emission: $447 / 60$ ) to check the nuclear counter staining.

\section{Results}

To obtain the desired optimal in vivo sensitivity, we synthesized a near infrared (NIR) fluorogenic cyanine $\mathrm{pH}$-sensitive (CypH-1) dye by placing an amino group near the conjugated double bonds on a $\mathrm{Cy} 7$ analog (Fig 1A). CypH-1 was prepared by reacting a commercial available IR-775 dye with 4-(dimethylamino) phenol using sodium hydride as a base in anhydrous dimethylformamide. (Supporting Information.)

CypH-1 has almost no fluorescence at neutral and basic conditions $(\geq 7.0)$, but fluoresces brightly when the solution is acidic ( $\leq \mathrm{pH} 5.0)$ (Fig. 1B). The excitation and emission maxima of $\mathrm{CypH}-1$ are 760 and $777 \mathrm{~nm}$, respectively (Supporting Information, Fig S1). The quantum yield $(\Phi)$ of $\mathrm{CypH}-1$ at $\mathrm{pH} 7.4$ and 4.0 are $0.17 \%$ and $6.9 \%$, respectively, representing up to a 40-fold difference in fluorescence signal intensity (Supporting Information, Fig S2). Near infrared fluorescence (NIRF) image confirmed intense fluorescence signal at $\mathrm{pH}$ 5.0, less intense fluorescence at $\mathrm{pH}$ 6.0, and no detectable signal at $\mathrm{pH} 7.0$ or 8.0 (Fig. $1 \mathrm{C})$.

We then evaluated the intracellular localization properties of CypH-1 by using an immortalized human ovarian adenocarcinoma cell line, SKOV-3, for cell uptake and live cell fluorescence microscopy. CypH-1 $(1 \mu \mathrm{M})$ in culture media was incubated with SKOV-3 cells grown on plates for 30 minutes followed by microscopy using appropriate filters. As shown in Fig. 2 intracellular fluorescence was detected clearly with negligible background signal. The intracellular distribution of $\mathrm{CypH}-1$ was compared to three organelles-lysosomes, mitochondria, and the endoplasmic reticulum (ER)-using commercially available labeling reagents, LysoTracker, MitoTracker, and ER-Tracker, respectively. Intracellular $\mathrm{CypH}-1$ signal was found to overlap with the signal of LysoTracker, and MitoTracker, but not with ER-Tracker. 
A

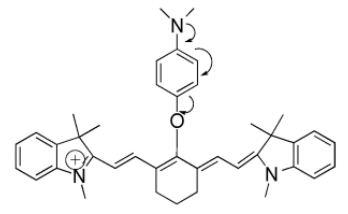

Non-fluorescence

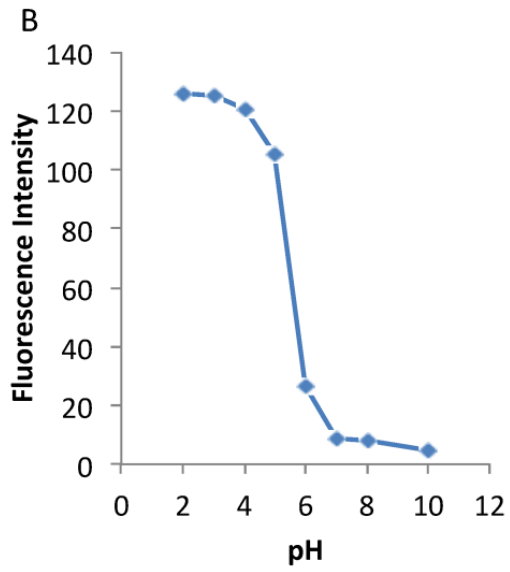

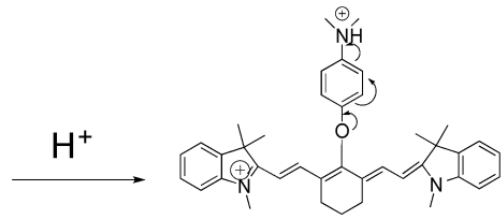

Fluorescence
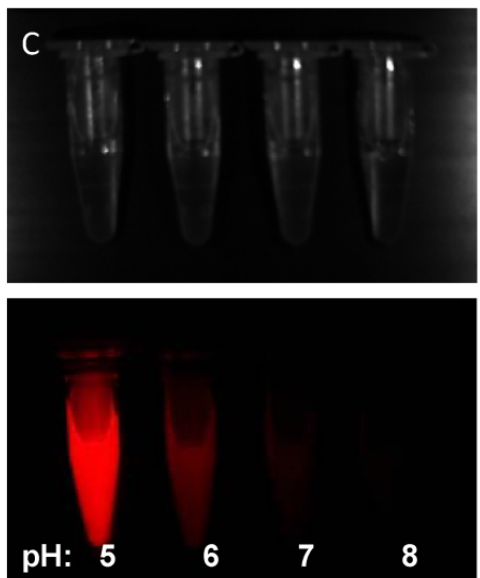

Fig 1: (A). The schematic diagram of the fluorescence activation of $\mathrm{CypH}-1$. Arrows indicate the delocalization of electrons. (B) $\mathrm{pH}$ sensitivity of $\mathrm{CypH}-1$ and its intracellular distribution. $\mathrm{pH}$ response of $\mathrm{CypH}-1$ was measured with $\mathrm{Ex}=740 \mathrm{~nm}$ and $\mathrm{Em}=785 \mathrm{~nm}$. The pKa is 5.3. (C) Bright field and NIR fluorescence images of CypH-1 in the $\mathrm{pH}$ range $5-8$.

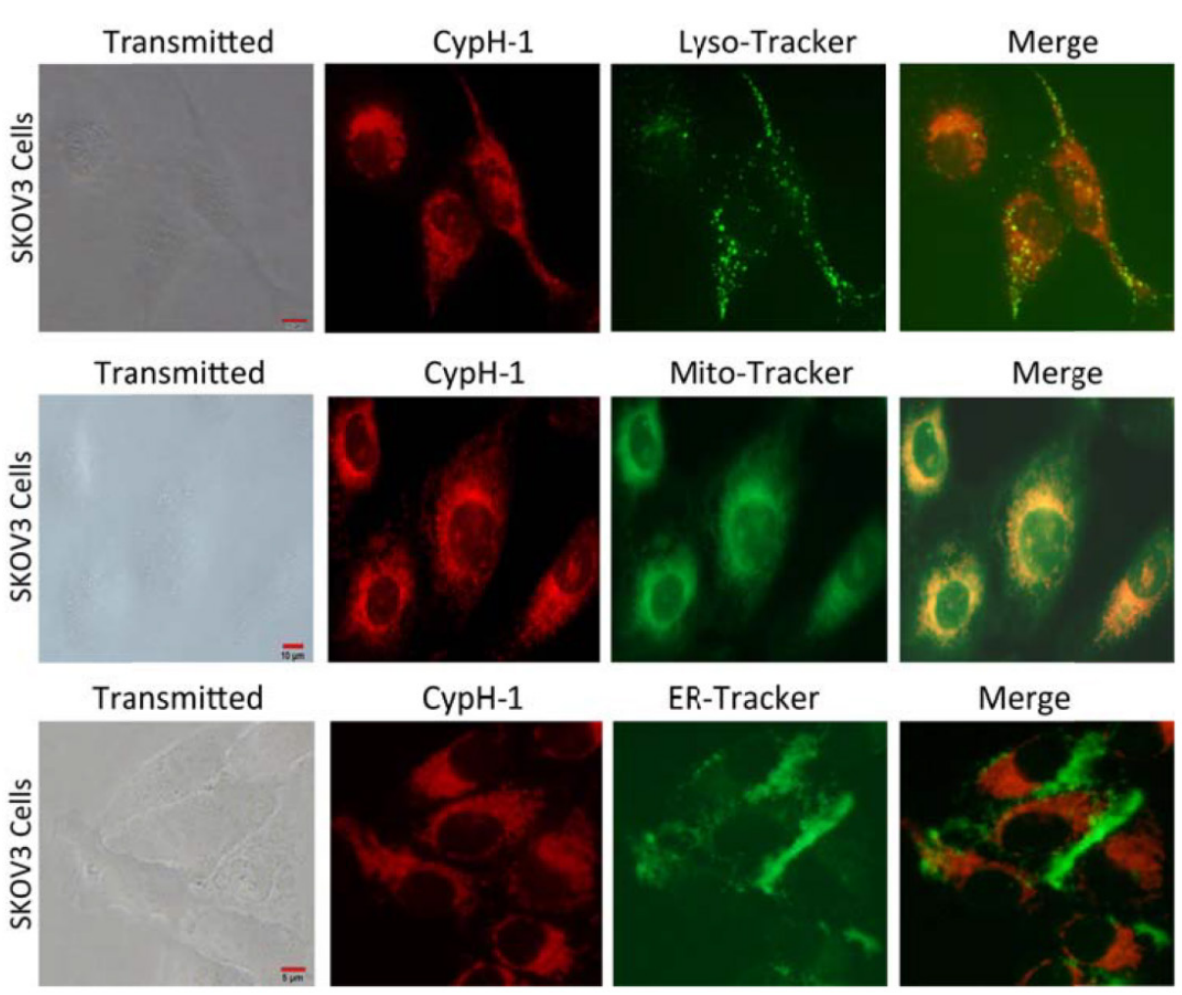

Fig 2: Intracellular distribution of $\mathrm{CypH}-1$. SKOV3 cells were incubated with $\mathrm{CypH}-1(1 \mu \mathrm{M})$ for 20 min, washed and then incubated with each organelle tracker $(0.5 \mu \mathrm{M})$ for $1 \mathrm{~h}$. The images showed $\mathrm{CypH}-1$ signal (red) co-registered with the signal of lyso-tracker and mito-tracker, but not ER tracker.

To evaluate the in vivo performance of CypH-1 a xenograft murine model was generated by the intraperitoneal (IP) inoculation of SKOV-3 cells that have been modified to express luciferase and green fluorescence protein (GFP). Tumor growth was followed by bioluminescence imaging (data not shown) and approximately two weeks after inoculation, CypH-1 (20 nmole in $100 \mathrm{uL}$ of phosphate buffered saline (PBS) was administered intraperitoneally. The mice were sacrificed 3 hours post-IP injection of CypH-1 
and the abdominal cavities were exposed. Without any washing procedures or subsequent handling, whole body GFP and NIRF images were acquired using a preclinical reflectance optical imaging system (IVIS-200). Since all tumors expressed GFP the green fluorescence signal corresponded to grossly visible tumors seen under white light (Fig. 3A). Fluorescence imaging using the NIR filters revealed precise signal co-localization with GFP-positive lesions (Fig. 3A). To further characterize additional disseminated lesions of varying size, tumors and several intraabdominal major organs (kidney, liver, spleen, stomach, and intestine) were resected and imaged with a zoomed field-of-view using a separate fluorescent imaging system (Maestro). Again, there was good agreement between NIRF and GFP signals indicating accurate detection of viable tumors (Fig. 3B).

Further analysis of a tiny metastatic implant in the spleen revealed an interesting distribution of CypH-1 signal that was most intense in the periphery of the lesion that measured approximately $1 \mathrm{~mm}$ in diameter (Fig. 4A). A kinetic study was also performed to monitor the time needed for the signal de-

A.

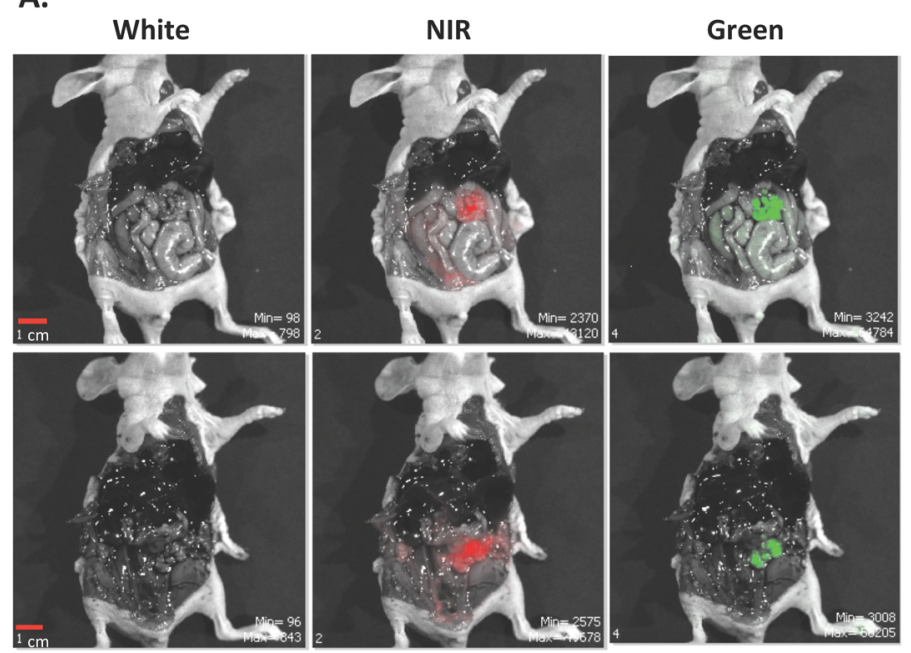

c.

C. NIR singal in various mice tissue (Ex Vivo)

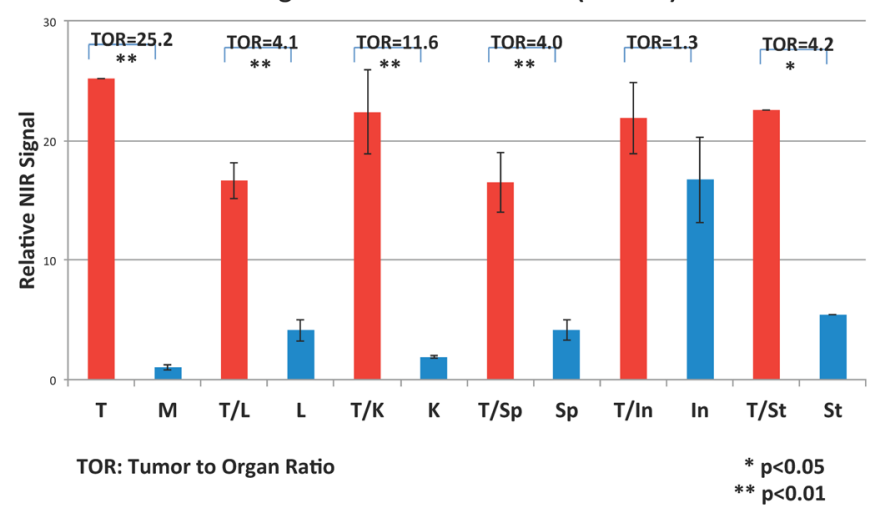

velopment. A spleen with a metastatic tumor was submerged into the CypH-1 solution $(1 \mu \mathrm{M})$, and imaged at different time intervals directly without washing (Fig 4B). The CypH-1 signal was developed quickly, in less than $3 \mathrm{~min}$, and stabilized after $20 \mathrm{~min}$.

This peripheral distribution pattern of the signal was confirmed at the microscopic level. As shown in Fig. 5A the NIRF signal was seen on the surface of a resected tumor (Fig. 5A, upper row) and at the interface between tumor and spleen (Fig. 5A, lower row). The distribution of the $\mathrm{pH}$ signal is distinct from the GFP signal, which appears uniformly distributed throughout the tumor. The sharp interface strongly suggests the physiological difference between the tumor and normal tissues. Under higher magnification (40X), the fluorescent signal was only seen on the top 5-7 layers of the tumor cells (Fig 5B). High signal was found in the cytoplasm of tumor cells and not on the extracellular membrane. Since $\mathrm{CypH}-1$ was administered intraperitoneally, it is possible that the peripheral signal observed in the tissues simply reflects the degree of absorption or penetration of the probe.
B.
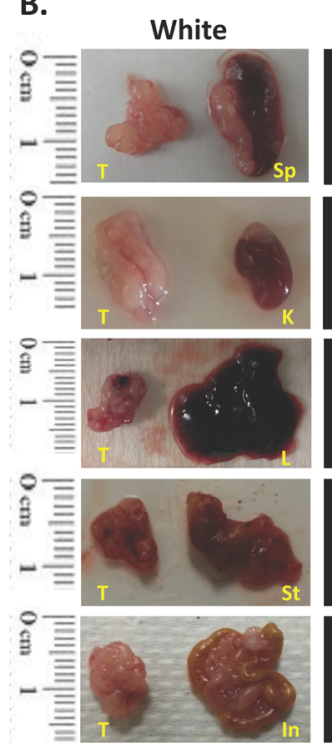
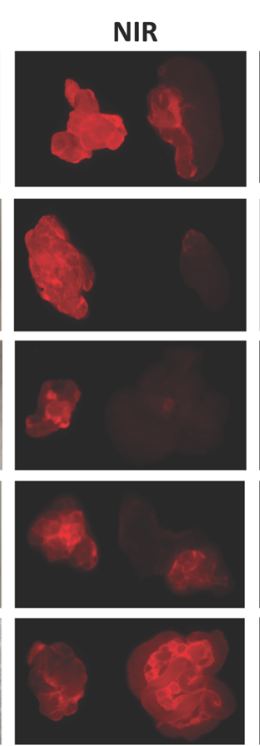

Green
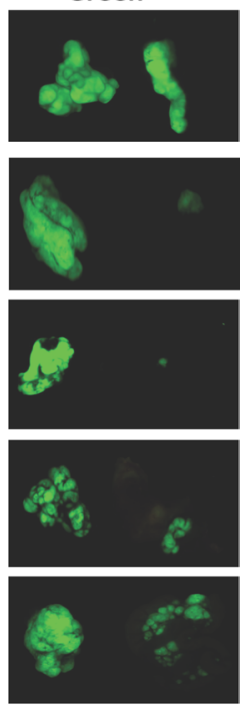

Fig 3: In vivo and ex vivo images of $\mathrm{CypH}-1$ in ovarian cancer model. (A) Nude mice with GFP positive SKOV3 tumor were imaged $3 \mathrm{~h}$ after IP injection of CypH-1. Green fluorescence indicated the location of the GFP+ tumors, which were also found NIRF positive. (B). Ex-vivo images of individual organ, and (C) the quantification of the tumor to organ ratio (TOR). T: tumor; In: intestine, K: kidney, L: liver, M: muscle, Sp: spleen, and St: stomach. 
A. White

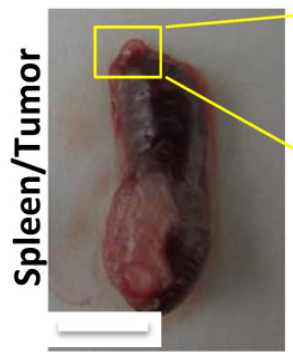

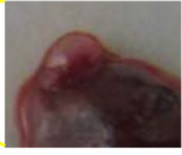
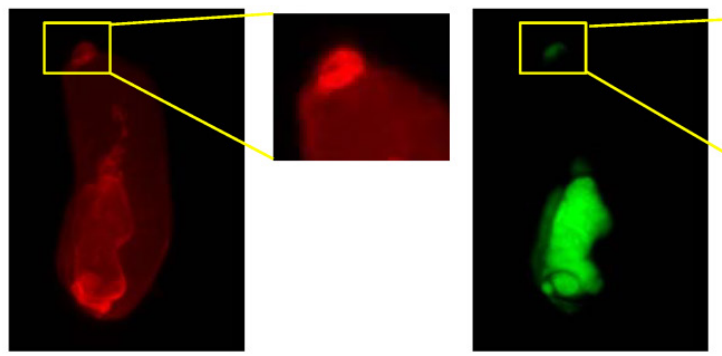

Green

B.
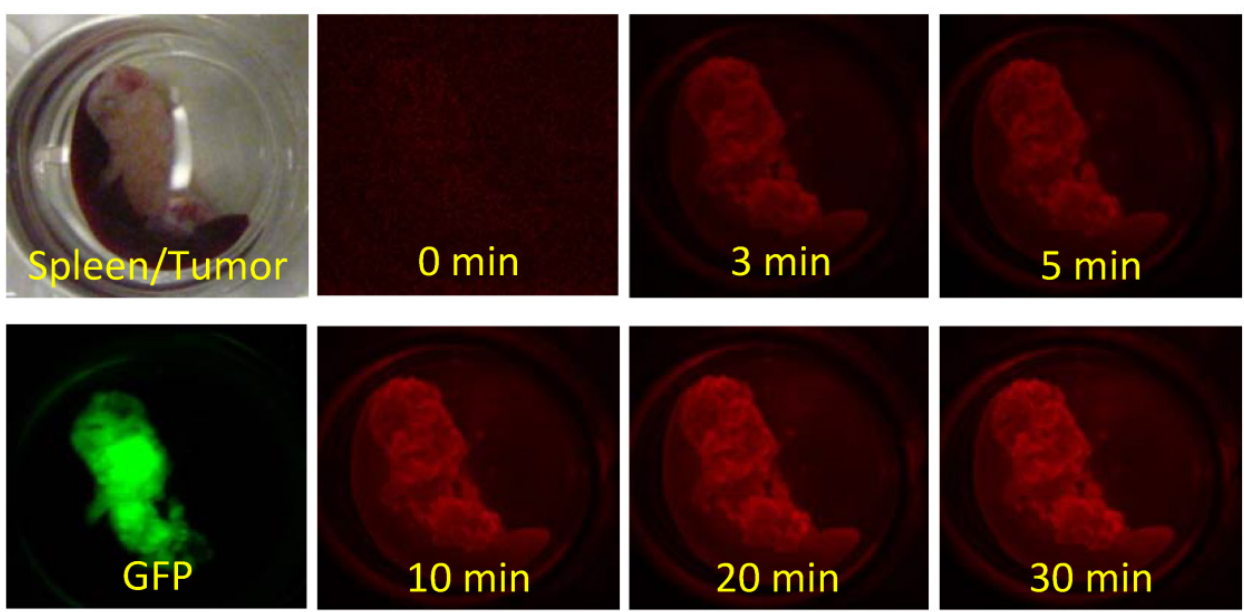

Fig 4. (A) The macroscopic images showed different signal intensity in tumors. The $\mathrm{CypH}-1$ signal highlighted the periphery of the tumor (GFP). The small tumor on the tip of spleen is less than $1 \mathrm{~mm}$. (B) Quick responsive of $\mathrm{CypH}-1$ with the excised tissue. The tumor on spleen was incubated with $\mathrm{CypH}-1(1 \mu \mathrm{M})$ and imaged at different time points.

\section{A.}
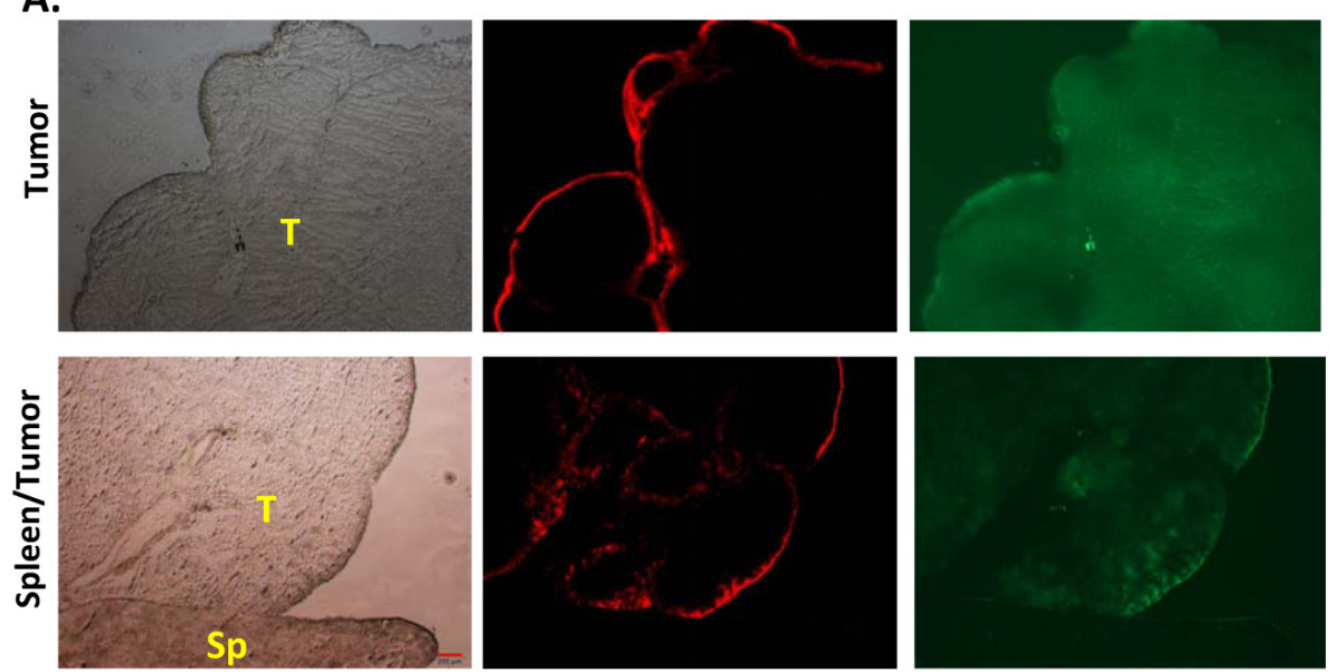

B.
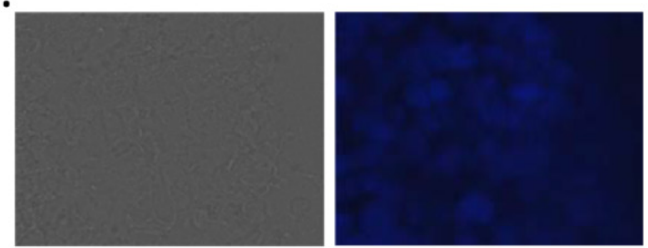

DAPI

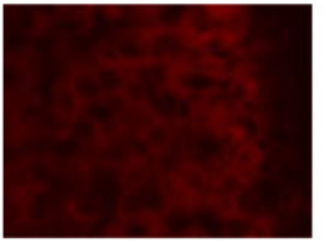

CypH-1

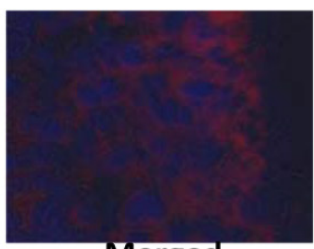

Merged

Fig 5. Histological correlation of the fluorescent signal of tumor and normal tissues. (A) The pH signal was only seen on the edge of the tumor (top row), but not in normal spleen tissue (bottom row). T: tumor; Sp: spleen. 4X. (B): The fluorescence signal was in the cytoplasm of the top 5 to 7 layers of tumor cells (40X). 


\section{Discussion}

CypH-1, a simple $\mathrm{pH}$ responsive fluorogenic dye without a targeting moiety, has shown great promise in detecting superficial small ovarian tumors. Its construct enabled alteration of fluorescence intensity through a photo-induced electron transfer (PeT) mechanism, which involves signal quenching by the lone pair electrons from the amine group (Fig. 1A). When the amine is protonated under acidic conditions, fluorescence is de-quenched resulting in a strong signal (Fig. 1).

Although tumor $\mathrm{pH}_{\mathrm{i}}$ is neutral, some organelles, such as lysosome and mitochondria, are known to be acidic. CypH-1 precisely co-localized with LysoTracker (Fig. 2, top row) strongly supporting its rapid lysosomal uptake and also fully explains CypH-1's activation in the low $\mathrm{pH}$ environment of this organelle $(\mathrm{pH} \sim 5)$. Interestingly, $\mathrm{CypH}-1$ was also activated in mitochondria, again strongly supported by the known acidic compartments involved in the chemiosmotic production of ATP by this organelle (Fig. 2, second row) [37]. In contrast to the observed lysosome and mitochondria localization, СypH-1 signal was not observed in the ER or the cell nucleus. Since CypH-1 emits no fluorescence in neutral biological $\mathrm{pH}$ cells incubated with this compound can be imaged immediately without any washing procedures.

It is important to emphasize that both gross in situ and close up ex vivo imaging show overall favorable low background NIRF signal following the intraperitoneal administration of CypH-1 in the absence of a washing procedure. The relatively low background tissue signal enables high tumor contrast even for tiny lesions that are marginally visible in white light. For example, small lesions, $<1 \mathrm{~mm}$, were detected clearly in liver (Fig. 3B) and spleen (Fig. 4A). Fluorescence signal ratio of tumor to normal muscle was 25.2:1 (Fig. 3C). When compared to normal organs, high signal contrast was also observed. The tumor to normal tissue ratios in kidney, liver, spleen, and stomach were $12,4,4$, and 4, respectively. The only exception was the intestine, where the tumor signal was only slightly higher than the background (ratio $=1.3$ ). The diffuse background signal from the gastrointestinal tract is likely due to nonspecific fluorescence from the diet ingested by the animals.

CypH-1 clearly detects physiologically relevant acidic conditions likely created by a combination of extracellular and intracellular changes occurring within tumors. The peripheral signal in the histological section showed a limited penetration of $\mathrm{CypH}-1$ (Fig 5A). The intracellular NIR fluorescence was only seen on the surface layers of the tumor, suggesting a significant difference in the permeability between the tumor and normal tissues (Fig 5B). Tissues in the acidic area, which is usually high in proteolysis activity, may be more permeable than in the neutral area $[9,10]$. The fast dynamics of tumor cell metabolism, could also advance the uptake of $\mathrm{CypH}-1$, resulting in a high tumor to background contrast. $\mathrm{CypH}-1$ is non-fluorescent in normal tissues but robustly fluoresces when localized within neoplastic lesions.

The high tumor to background contrast (Fig 3) and quick development of fluorogenic signal (Fig 4B) suggest that this type of $\mathrm{pH}$ dyes has great potential in guiding biopsy or surgical procedures in real time. CypH-1 is a single component agent, which is small and simple. The protonation of the molecule is a nearly instantaneous reaction, so the fluorescence development is rapid. This feature permits the use of CypH-1 as a simple solution that is sprayed directly onto the tissues within the operative field without the need for a long waiting period as required for most intravenously administered imaging agents. Moreover, as the acidic environment is a universal hallmark of cancer [1], the optimized dye could potentially be applied to detect various types of tumors. Conjugating of specific tumor targeting ligands, such as antibodies, peptides or aptamers, for each type of tumor might not be needed. The simplicity of its chemical structure would make the scale up preparation economical and make the clinical transition more feasible. Another significant advantage of a cancer spray is the required dose. If a dye could be sprayed onto only a specific area prior to or during a procedure, the total administered dose will be significantly lower than what is required for an intravenous route, and thus reducing the potential for toxicity. These features are well suited for rapid clinical translation in the form of an intraoperative system to augment the detection of tiny metastatic implants important for optimal cytoreductive surgery in ovarian cancer malignancies $[38,39]$.

Although CypH-1 showed good contrast in this study, its $\mathrm{pKa}$ is lower than the reported tumor $\mathrm{pH}_{\mathrm{e}}$, $\mathrm{pH}$ 6.4-7.1.[4, 6-8]. Therefore, a fluorogenic dye with a higher $\mathrm{pKa}$ maybe better suited in imaging the extracellular tumor $\mathrm{pH}$. Additionally, the dye should not penetrate the cell membrane, as the internalized dye will interact with the intracellular acidic compartments. Prior reports have suggested that different tumor types may demonstrate varying degrees of $\mathrm{pH}$ changes in their microenvironments [40,41]; it is possible that additional chemical modifications could lead to more $\mathrm{pH}$ responsive probes for specific niche applications.

Recently, many new fluorescence imaging systems, such as endoscopes [42, 43], wide-field video 
cameras [32, 44], and goggles $[45,46]$, have been developed for clinical applications. These imaging systems certainly could further accelerate the clinical translation of this novel molecular imaging probe that targets the acidic microenvironment.

\section{Conclusion}

Our data indicated that a permeable $\mathrm{pH}$-sensitive imaging agent may augment the detection of ovarian tumors. The probe was picked up rapidly by the top few layers of cancer cells, probably due to the acidic microenvironment associated leakiness and high metabolic rate of cancerous tissues. Since an acidic microenvironment is a common feature of most solid tumors, and the $\mathrm{pH}$ reaction is a near instantaneous reaction, our approach could have a significant impact on clinical applications. The $\mathrm{pH}$-triggered activation permits high signal to background ratios of lesions as small as $1 \mathrm{~mm}$ without the need for a clearance procedure to remove any excess compound. This type of fluorogenic dyes may be intraperitoneally or topically applied to an area of suspected neoplastic involvement prior to or even during surgery, without the need for intravenous administration, reducing the potential for systemic toxicity.

\section{Supplementary Material}

Supporting Information. Figures S1-S3.

http://www.thno.org/v05p1166s1.pdf

\section{Acknowledgements}

The authors like to thank Dr. Daniel Lee for editing the manuscript. We thank the NMR facility at University of Texas M.D. Anderson Cancer Center for their assistance in acquiring chemical analysis data. This research was supported in part by NIH CA135312, GM094880 and the Oshman Foundation.

\section{Disclosure}

The authors declare no competing financial interests.

\section{References}

1. Hanahan D, Weinberg RA. Hallmarks of cancer: the next generation. Cell. 2011;144:646-74.

2. Schiavoni G, Gabriele L, Mattei F. The tumor microenvironment: a pitch for multiple players. Front Oncol. 2013;3:90.

3. Estrella V, Chen T, Lloyd M, Wojtkowiak J, Cornnell HH, Ibrahim-Hashim A, et al. Acidity generated by the tumor microenvironment drives local invasion. Cancer Res. 2013;73:1524-35.

4. Webb BA, Chimenti M, Jacobson MP, Barber DL. Dysregulated pH: a perfect storm for cancer progression. Nat Rev Cancer. 2011:11:671-7.

5. Gatenby RA, Gillies RJ. Why do cancers have high aerobic glycolysis? Nat Rev Cancer. 2004;4:891-9

6. Choi SY, Collins CC, Gout PW, Wang Y. Cancer-generated lactic acid: a regulatory, immunosuppressive metabolite? J Pathol. 2013;230:350-5.

7. Calcinotto A, Filipazzi P, Grioni M, Iero M, De Milito A, Ricupito A, et al. Modulation of microenvironment acidity reverses anergy in human and murine tumor-infiltrating T lymphocytes. Cancer Res. 2012;72:2746-56.

8. De Milito A, Canese R, Marino ML, Borghi M, Iero M, Villa A, et al. pH-dependent antitumor activity of proton pump inhibitors against human melanoma is mediated by inhibition of tumor acidity. Int J Cancer. 2010;127:207-19

9. Rozhin J, Sameni M, Ziegler G, Sloane BF. Pericellular $\mathrm{pH}$ affects distribution and secretion of cathepsin B in malignant cells. Cancer Res. 1994;54:6517-25.

10. Busco G, Cardone RA, Greco MR, Bellizzi A, Colella M, Antelmi E, et al. NHE1 promotes invadopodial ECM proteolysis through acidification of the peri-invadopodial space. FASEB J. 2010;24:3903-15.

11. Galande $\mathrm{AK}$, Weissleder $\mathrm{R}$, Tung $\mathrm{CH}$. Fluorescence probe with a $\mathrm{pH}$-sensitive trigger. Bioconjug Chem. 2006;17:255-7.

12. Gil PR, Nazarenus M, Ashraf S, Parak WJ. pH-sensitive capsules as intracellular optical reporters for monitoring lysosomal $\mathrm{pH}$ changes upon stimulation. Small. 2012;8:943-8.

13. Weerakkody D, Moshnikova A, Thakur MS, Moshnikova V, Daniels J, Engelman DM, et al. Family of $\mathrm{pH}$ (low) insertion peptides for tumor targeting. Proc Natl Acad Sci U S A. 2013;110:5834-9.

14. Kim HJ, Heo $\mathrm{CH}$, Kim HM. Benzimidazole-based ratiometric two-photon fluorescent probes for acidic $\mathrm{pH}$ in live cells and tissues. J Am Chem Soc. 2013;135:17969-77.

15. Cruz-Monserrate Z, Roland CL, Deng D, Arumugam T, Moshnikova A, Andreev $\mathrm{OA}$, et al. Targeting pancreatic ductal adenocarcinoma acidic microenvironment. Sci Rep. 2014;4:4410.

16. Ling D, Park W, Park SJ, Lu Y, Kim KS, Hackett MJ, et al. Multifunctional tumor $\mathrm{pH}$-sensitive self-assembled nanoparticles for bimodal imaging and treatment of resistant heterogeneous tumors. J Am Chem Soc. 2014;136:5647-55.

17. Ahmed F, Pakunlu RI, Srinivas G, Brannan A, Bates F, Klein ML, et al. Shrinkage of a rapidly growing tumor by drug-loaded polymersomes: pH-triggered release through copolymer degradation. Mol Pharm. 2006;3:340-50

18. Huang $\mathrm{Y}$, Tang $\mathrm{Z}$, Zhang $\mathrm{X}, \mathrm{Yu} \mathrm{H}$, Sun $\mathrm{H}$, Pang $\mathrm{X}$, et al. $\mathrm{pH}$-Triggered charge-reversal polypeptide nanoparticles for cisplatin delivery: preparation and in vitro evaluation. Biomacromolecules. 2013;14:2023-32.

19. Han J, Burgess K. Fluorescent indicators for intracellular $\mathrm{pH}$. Chem Rev. 2010;110:2709-28.

20. Adie EJ, Kalinka S, Smith L, Francis MJ, Marenghi A, Cooper ME, et al. A $\mathrm{pH}$-sensitive fluor, CypHer 5, used to monitor agonist-induced G protein-coupled receptor internalization in live cells. Biotechniques. 2002;33:1152-4, 6-7.

21. Wang L, Fan Z, Zhang J, Changyi Y, Huang C, Gu Y, et al. Evaluating tumor metastatic potential by imaging intratumoral acidosis via $\mathrm{pH}$-activatable near-infrared fluorescent probe. Int J Cancer. 2015;136:E107-16.

22. Zhang XX, Wang Z, Yue X, Ma Y, Kiesewetter DO, Chen X. pH-sensitive fluorescent dyes: are they really $\mathrm{pH}$-sensitive in cells? Mol Pharm. 2013;10:1910-7.

23. Zhang Z, Achilefu S. Design, synthesis and evaluation of near-infrared fluorescent $\mathrm{pH}$ indicators in a physiologically relevant range. Chem Commun (Camb). 2005:5887-9.

24. Tang B, Yu F, Li P, Tong L, Duan X, Xie T, et al. A near-infrared neutral pH fluorescent probe for monitoring minor $\mathrm{pH}$ changes: imaging in living HepG2 and HL-7702 cells. J Am Chem Soc. 2009;131:3016-23.

25. Cooper ME, Gregory S, Adie E, Kalinka S. pH-sensitive cyanine dyes for biological applications. J Fluorescence. 2002;12:425-9.

26. Lee H, Akers W, Bhushan K, Bloch S, Sudlow G, Tang R, et al. Near-infrared $\mathrm{pH}$-activatable fluorescent probes for imaging primary and metastatic breast tumors. Bioconjug Chem. 2011;22:777-84.

27. Li C, Greenwood TR, Bhujwalla ZM, Glunde K. Synthesis and characterization of glucosamine-bound near-infrared probes for optical imaging. Org Lett. 2006;8:3623-6.

28. Hoogendoorn S, Habets KL, Passemard S, Kuiper J, van der Marel GA, Florea $\mathrm{BI}$, et al. Targeted $\mathrm{pH}$-dependent fluorescent activity-based cathepsin probes. Chem Commun (Camb). 2011;47:9363-5.

29. Nick AM, Coleman RL, Ramirez PT, Sood AK. A framework for a personalized surgical approach to ovarian cancer. Nat Rev Clin Oncol. 2015;12:239-45.

30. Aletti GD, Gostout BS, Podratz KC, Cliby WA. Ovarian cancer surgical resectability: relative impact of disease, patient status, and surgeon. Gynecol Oncol. 2006;100:33-7.

31. Sheth RA, Upadhyay R, Stangenberg L, Sheth R, Weissleder R, Mahmood U. Improved detection of ovarian cancer metastases by intraoperative quantitative fluorescence protease imaging in a pre-clinical model. Gynecol Oncol. 2009;112:616-22

32. van Dam GM, Themelis G, Crane LM, Harlaar NJ, Pleijhuis RG, Kelder W, et al. Intraoperative tumor-specific fluorescence imaging in ovarian cancer by folate receptor-alpha targeting: first in-human results. Nat Med. 2011;17:1315-9.

33. Tung $\mathrm{CH}$. Colorful lighting in the operating room. Quant Imaging Med Surg. 2013;3:186-8

34. Han MS, Tung $\mathrm{CH}$. Lessons learned from imaging mouse ovarian tumors: the route of probe injection makes a difference. Quant Imaging Med Surg. 2014;4:156-62.

35. Seim KL, Obermeyer AC, Francis MB. Oxidative modification of native protein residues using cerium(IV) ammonium nitrate. J Am Chem Soc. 2011:133:16970-6.

36. Yamane T, Hanaoka K, Muramatsu Y, Tamura K, Adachi Y, Miyashita Y, et al. Method for enhancing cell penetration of Gd3+-based MRI contrast agents by 
conjugation with hydrophobic fluorescent dyes. Bioconjug Chem. 2011;22:2227-36.

37. Bonnet S, Archer SL, Allalunis-Turner J, Haromy A, Beaulieu C, Thompson R, et al. A mitochondria- $\mathrm{K}+$ channel axis is suppressed in cancer and its normalization promotes apoptosis and inhibits cancer growth. Cancer Cell. 2007;11:37-51.

38. Bristow RE, Tomacruz RS, Armstrong DK, Trimble EL, Montz FJ. Survival effect of maximal cytoreductive surgery for advanced ovarian carcinoma during the platinum era: a meta-analysis. J Clin Oncol. 2002;20:1248-59.

39. Eisenkop SM, Friedman RL, Wang HJ. Complete cytoreductive surgery is feasible and maximizes survival in patients with advanced epithelial ovarian cancer: a prospective study. Gynecol Oncol. 1998;69:103-8.

40. Gerweck LE, Seetharaman K. Cellular $\mathrm{pH}$ gradient in tumor versus normal tissue: potential exploitation for the treatment of cancer. Cancer Res. 1996;56:1194-8.

41. Engin K, Leeper DB, Cater JR, Thistlethwaite AJ, Tupchong L, McFarlane JD. Extracellular $\mathrm{pH}$ distribution in human tumours. Int J Hyperthermia. 1995;11:211-6.

42. Hsiung PL, Hardy J, Friedland S, Soetikno R, Du CB, Wu AP, et al. Detection of colonic dysplasia in vivo using a targeted heptapeptide and confocal microendoscopy. Nat Med. 2008;14:454-8.

43. Funovics MA, Alencar H, Su HS, Khazaie K, Weissleder R, Mahmood U. Miniaturized multichannel near infrared endoscope for mouse imaging. Mol Imaging. 2003;2:350-7.

44. Knapp DW, Adams LG, Degrand AM, Niles JD, Ramos-Vara JA, Weil AB, et al. Sentinel lymph node mapping of invasive urinary bladder cancer in animal models using invisible light. Eur Urol. 2007;52:1700-8

45. Liu Y, Bauer AQ, Akers WJ, Sudlow G, Liang K, Shen D, et al. Hands-free, wireless goggles for near-infrared fluorescence and real-time image-guided surgery. Surgery. 2011;149:689-98.

46. Wang X, Bhaumik S, Li Q, Staudinger VP, Yazdanfar S. Compact instrument for fluorescence image-guided surgery. J Biomed Opt. 2010;15:020509. 